\title{
Os conhecimentos tradicionais associados à biodiversidade amazônica: proteção jurídica e sustentabilidade
}

\author{
Traditional knowledge associated with amazon biodiversity: \\ juridical protection and sustainability
}

Ana Carolina Couto Matheus

Universidade Federal do Acre - UFAC

Resumo Considerando a imprescindível inter-relação dos conhecimentos tradicionais dos povos da Amazônia com a sustentabilidade, o objeto basilar da produção científica proposta é estudar a proteção jurídica aplicada aos conhecimentos tradicionais associados à biodiversidade amazônica. Comporta necessariamente um tratamento transdisciplinar, pois as categorias de construções da realidade são diversas, e, embora diferentes, encontram-se profundamente interligadas ou interdependentes. O método utilizado na fase de investigação e na fase de tratamento dos dados foi o indutivo. Nas distintas fases da pesquisa foram acionadas as técnicas do referente, da categoria, do conceito operacional, da pesquisa bibliográfica e do fichamento. $\mathrm{O}$ desenvolvimento do tema pautou-se pela persecução dos objetivos gerais e específicos que nortearam a produção. O relatório se encerra com as considerações finais e consubstancia o resultado de todos os achados da pesquisa acadêmica, findando por confirmar a hipótese inicialmente concebida, a fim de alcançar o tratamento sustentável dos conhecimentos tradicionais associados à biodiversidade amazônica. Palavras-chave: Conhecimentos Tradicionais Associados à Biodiversidade. Povos Tradicionais Amazônicos. Sustentabilidade. Proteção Jurídica.

ABSTRaCr Considering the essential interrelationship of the traditional knowledge of the Amazonian peoples with sustainability, the basic objective of the proposed scientific production is to study the legal protection applied to the traditional knowledge associated to the Amazonian biodiversity. It necessarily entails a transdisciplinary treatment, since the categories of constructions of reality are diverse, and although different, they are deeply interconnected or interdependent. The method used in the research phase and in the data treatment phase was the inductive one. In the various phases of the research the techniques of the referent, the category, the operational concept, the bibliographical research and the file were triggered. The development of the theme was guided by the pursuit of the general 
and specific objectives that guided production. The report closes with the conclusions and consolidates the results of all the findings of the academic research, in order to confirm the hypothesis initially conceived, in order to achieve the sustainable treatment of the traditional knowledge associated to the Amazonian biodiversity.

Keywords: Traditional Knowledge Associated with Biodiversity. Traditional Amazonian People. Sustainability. Legal Protection.

\section{INTRODUÇÃo}

O objeto deste trabalho é o estudo da proteção jurídica e da sustentabilidade dos conhecimentos tradicionais associados à biodiversidade amazônica. A escolha do tema justifica-se em razão da importância e complexidade. Comporta necessariamente um tratamento transdisciplinar, uma vez que as categorias de construções da realidade são diversas, e, embora diferentes, encontram-se profundamente interligadas ou interdependentes.

Assim posto, o problema da pesquisa em testilha é evidenciar a sustentabilidade dos conhecimentos tradicionais associados à biodiversidade amazônica e a necessidade de melhorar a proteção jurídica desses importantes conhecimentos geracionais. $\mathrm{O}$ aludido problema concentra seus esforços na busca de substituir o sistema de patentes, bem como, o sistema de garantia dos direitos de autor, inadequados para proteger as comunidades tradicionais.

Todo trabalho encontra-se parametrizado teoricamente na Constituição Federal de 1988, na legislação nacional e estrangeira, em vasta literatura nacional e estrangeira, artigos de revistas jurídicas especializadas e jurisprudência pertinente ao tema.

Para o equacionamento do problema suscita-se a seguinte hipótese, a saber: a floresta amazônica está inserida além do Brasil, em territórios de outros países sul-americanos como a Bolívia, a Colômbia, o Equador, a Guiana, a Guiana Francesa, o Peru, o Suriname e a Venezuela, portanto, sua conservação exige, necessariamente, o compromisso e a organização de todos esses países.

O trabalho investiga juridicamente se existe a possibilidade de, neste cenário transnacional, exercer-se a tutela sustentável dos conhecimentos tradicionais associados à biodiversidade amazônica por meio da proteção jurídica.

Em função da problemática e da hipótese, o objetivo geral do trabalho consiste em analisar a proteção jurídica dos conhecimentos tradicionais associados à biodiversidade amazônica, considerando a imprescindível inter-relação dos conhecimentos tradicionais dos povos da Amazônia com a conservação ambiental.

A hipótese retromencionada impulsionou o desenho dos seguintes objetivos específicos para se alcançar os achados pretendidos: verificar no ordenamento vigente o arcabouço jurídico aplicado aos conhecimentos tradicionais dos povos da Amazônia; enfatizar a limitada proteção que oferecem os direitos nacionais e a tutela internacional em vigor relacionada aos conhecimentos tradicionais associados à biodiversidade amazônica, considerando sua imprescindível inter-relação com a sustentabilidade; sugerir o alcance da sustentabilidade no tratamento dos conhecimentos tradicionais associados à biodiversidade amazônica. 
O marco de referência privilegia a construção teórica segundo a qual estuda a proteção jurídica dos conhecimentos tradicionais associados à biodiversidade amazônica e desdobra-se por meio de três pontos principais: o primeiro estuda os conhecimentos tradicionais dos povos da Amazônia; o segundo enfatiza a legislação aplicada aos conhecimentos tradicionais, a limitada proteção que oferecem os direitos nacionais e a tutela internacional; e o terceiro verifica o tratamento sustentável dos conhecimentos tradicionais associados à biodiversidade amazônica.

Pelo método de abordagem indutivo, fonte de pesquisa bibliográfica e legal relativa aos conhecimentos tradicionais associados à biodiversidade amazônica, serão pesquisadas e confrontadas as partes de um todo para que se possa ter uma visão generalizada. Durante as diversas fases da pesquisa serão utilizadas as técnicas do referente, da categoria, do conceito operacional, do fichamento e com base em documentação indireta será realizada a pesquisa bibliográfica.

O trabalho em apreço finda com as considerações finais, em que serão apresentados pontos conclusivos abstraídos da pesquisa, a análise e a inferência das reflexões realizadas em relação à proteção jurídica e ao tratamento sustentável dos conhecimentos tradicionais associados à biodiversidade amazônica.

\section{OS CONHECIMENTOS TRADICIONAIS DOS POVOS DA AMAZÔNIA}

O Brasil é a nação com a maior diversidade biológica. Segundo Gregori (2013, p. 142), é um dos países do mundo com maior potencial de prospecção de novos produtos e processos derivados de plantas e de animais, muitos dos quais ainda nem descobertos.

Essa riqueza é foco do interesse e ganância de outras nações e, principalmente, das indústrias, que buscam novas fontes de pesquisa e domínio econômico, por meio dos mecanismos de propriedade intelectual, pela apropriação dos conhecimentos tradicionais (índios, seringueiros, ribeirinhos, castanheiros, pescadores, quilombolas, entre outros), acabam revelando ótimos caminhos para o acesso direto a plantas e animais, que servem de base para pesquisa científica, diminuindo tempo, custo e energia para obter novos medicamentos, cosméticos, produtos industriais, entre outros.

"Os povos indígenas, quilombolas e populações tradicionais produzem conhecimentos e inovações em diversas áreas, devendo ser tutelados" (MATHEUS, 2018, p. 93). Conhecimento tradicional é o conhecimento intergeracional dos povos amazônicos, transmitido oralmente e relacionados, diretamente, aos seus aspectos culturais, folclore, uso e manejo dos recursos naturais, importantes tanto para a conservação da diversidade biológica amazônica, quanto para o seu uso sustentável.

Os povos tradicionais tiveram o reconhecimento de sua existência formal apenas em 7 de fevereiro de 2007, por meio do Decreto Presidencial n. 6.040, que instituiu a Política Nacional de Desenvolvimento Sustentável dos Povos e Comunidades Tradicionais e define povos e comunidades tradicionais como grupos culturalmente diferenciados, que possuem formas próprias de organização social, que ocupam e usam territórios e recursos naturais como condição para sua reprodução cultural, social, religiosa, ancestral e econômica, utilizando conhecimentos, inovações e práticas gerados e transmitidos pela tradição. 
A função dessas populações para a conservação das áreas contempladas por recursos naturais é de suma relevância, pela forma do manejo nativo sustentável que desenvolvem nas florestas tropicais, com base no conhecimento milenar tradicional e comunitário, pautado na observação e experimentação, e pela relação de valorização e respeito com a natureza. Todas essas práticas contribuem para a reafirmação dos povos, tanto no que concerne às suas identidades culturais quanto aos espaços territoriais.

A Amazônia está localizada no centro-norte do continente sul-americano, área geográfica que corresponde à bacia hidrográfica do rio Amazonas. Os países que fazem parte da região amazônica são: Bolívia, Brasil, Colômbia, Equador, Guiana, Guiana Francesa, Peru, Suriname e Venezuela. No Brasil, a floresta amazônica abrange os Estados do Amazonas, Acre, Amapá, Rondônia, Pará e Roraima.

A Reserva Extrativista do Vale do Juruá, no Estado do Acre, sudoeste da região amazônica, considerada uma das regiões mais ricas em biodiversidade de todo o mundo, deixa claro que as intervenções realizadas pelas comunidades tradicionais do Vale do Juruá contribuem para sua conservação (BROWN e FREITAS, 2002, p. 41).

Essa diversidade foi alcançada não somente por obra da natureza, mas também pela ação humana e atividade das diversas etnias que compartilham o mesmo ambiente. $\mathrm{O}$ direito dos povos tradicionais permanecerem em seus lugares de origem e a necessidade de proteção ao meio ambiente justificam a existência de normatizações sobre a ocupação e a utilização dos recursos naturais, desde que sejam elaboradas mediante o consenso entre os interessados: o poder público, os povos tradicionais e estudiosos das inter-relações entre homem e meio ambiente.

Seringueiros, ribeirinhos, castanheiros, pescadores, quilombolas e índios revelam o acesso a plantas e animais, a base para pesquisa científica, objeto de interesse de outras nações e indústrias que buscam novas fontes de pesquisa e domínio econômico por meio da apropriação dos conhecimentos tradicionais.

Para Santilli (2005, p. 52), urge o reconhecimento de direitos sobre o patrimônio dos povos indígenas, quilombolas e povos tradicionais, e que tais povos também possam usufruir da exploração econômica de produto ou processo desenvolvido a partir de seus saberes tradicionais e do material genético existente em seu território, por meio de um sistema de repartição justa dos benefícios.

Os referidos conhecimentos abrangem técnicas de manejo de recursos naturais, métodos de caça e pesca, saberes acerca dos diversos ecossistemas, bem como, de propriedades farmacêuticas, alimentícias e agrícolas, além das próprias categorizações e classificações de espécies de fauna e flora utilizadas.

Para que os povos tradicionais possam exercer o direito de permanecer em áreas protegidas, é necessário estabelecer três critérios: o tempo de residência na área amazônica, a prática de atividades de baixo impacto ambiental e a prática de uma economia de subsistência.

Há estreita relação das florestas culturais na manutenção dos recursos naturais para além das unidades de conservação, pois nem todos os povos tradicionais estão inseridos nessas unidades e, por isso, vêm travando lutas para terem seus direitos territoriais reco- 
nhecidos nos instrumentos legais de proteção da floresta, tendo em vista sua significância à conservação da cultura e desses ecossistemas, desempenhando um valoroso papel na conservação dos recursos ambientais nas áreas em que habitam.

\begin{abstract}
Os conhecimentos tradicionais são convertidos em objeto de debate das medidas no âmbito de diversas políticas-públicas, como as relacionadas com a tutela dos direitos humanos, a preservação e promoção da diversidade biológica, a proteção da saúde, o desenvolvimento sustentável e particular, a utilização sustentável dos recursos biológicos, o progresso econômico e social de certas comunidades, povos e nações na defesa de certas identidades e patrimônios culturais (MASSAGUER, 1996, p. 318).
\end{abstract}

Conhecimento tradicional associado é o conjunto de saberes, transmitidos oralmente, de geração em geração. Para Berckes (1999, p. 4), é o corpo acumulativo de conhecimento, práticas e crenças das comunidades tradicionais sobre a relação entre os seres vivos (inclusive o homem) e o seu ambiente, que se desenvolve ao longo do tempo por intermédio de um processo repassado através de gerações por transmissão cultural.

\title{
2 A LegislaÇÃo aPLICADA AOS CONHECIMENTOS TRADICIONAIS, A LIMITADA PROTEÇÃO QUE OFERECEM OS DIREITOS NACIONAIS E A TUTELA INTERNACIONAL
}

A Lei n. 13.123/2015 dispõe sobre a proteção e o acesso ao Conhecimento Tradicional Associado (CTA), a repartição de benefícios para conservação e uso sustentável da biodiversidade; define no artigo $2^{\circ}$. CTA como informação ou prática de população indígena, comunidade tradicional ou agricultor tradicional sobre as propriedades ou usos diretos ou indiretos associada ao patrimônio genético.

Define comunidade tradicional como grupo culturalmente diferenciado que se reconhece como tal, possui forma própria de organização social, ocupa e usa territórios e recursos naturais como condição para a sua reprodução cultural, social, religiosa, ancestral e econômica, utilizando conhecimentos, inovações e práticas geradas e transmitidas pela tradição.

Reconhece como provedor de CTA a população indígena, a comunidade tradicional ou o agricultor tradicional que detém e fornece a informação sobre o CTA para o acesso; prevê no artigo $8^{\circ}$. a proteção dos CTAs ao patrimônio genético dos povos tradicionais e assegura sua participação nas tomadas de decisões.

Os direitos legais assegurados às populações tradicionais e sua inserção, ainda que timidamente, nas unidades de conservação de uso sustentável caracterizadas nas reservas extrativistas e reservas de desenvolvimento sustentável, têm importante papel na conservação dos recursos naturais, pois tais povos contribuem para evitar manejos artificiais que comprometam grandes áreas contínuas de florestas, sendo verdadeiros guardiões contra a extração ilegal de madeiras e as ações agrosilvopastoris.

A preocupação pelos conhecimentos tradicionais alcançou, nos últimos anos, crescente reconhecimento da comunidade internacional, pela Convenção sobre Diversidade Biológica e por meio de ações desenvolvidas pela ONU. 
Brasil, Panamá, Venezuela e Peru adotam leis que protegem os CTs de natureza técnica, vinculados a recursos genéticos. Entre as organizações internacionais sul-americanas, destacam-se o MERCOSUL e o TCA. O MERCOSUL necessita de uma instância supranacional de coordenação política, porque suas duas economias principais (Brasil e Argentina) seguem caminhos divergentes e nenhuma está disposta a abrir mão da soberania a favor da criação de uma superestrutura jurídica e regional.

Destaca-se o Protocolo de Nagoia que trata do acesso a recursos genéticos e a repartição justa e equitativa dos benefícios advindos de sua utilização. Na década de 60 a UNES$\mathrm{CO}$ debateu formas de proteger especificamente as expressões do folclore, intimamente relacionadas com as manifestações culturais das comunidades tradicionais.

A Conferência de Estocolmo, em 1972, e a Conferência das Nações Unidas para o Meio Ambiente e o Desenvolvimento (Rio-92) consagraram os princípios fundamentais do Direito Ambiental para que as Constituições supervenientes reconhecessem o meio ambiente ecologicamente equilibrado como direito fundamental.

O debate aprofundado sobre a proteção dos conhecimentos tradicionais iniciou em 1988, no Primeiro Congresso Internacional de Etnobiologia em Belém, no Pará. Comunidades indígenas se reuniram com cientistas e ambientalistas para discutir estratégias ante a rápida diminuição da diversidade cultural biológica no planeta.

Em 2000, a Conferência das Nações Unidas sobre Comércio e Desenvolvimento debateu formas de proteger informações, inovações e práticas das comunidades tradicionais indígenas e locais, reforçar a cooperação e o desenvolvimento para a conservação e uso Sustentável dos recursos biológicos.

Em 1992, o marco legislativo da proteção dos conhecimentos tradicionais no âmbito internacional é a Convenção sobre a Diversidade Biológica (CDB), que trata da conservação da diversidade biológica e o acesso aos recursos genéticos. Reconheceu o importante papel dos povos tradicionais na conservação e utilização de forma sustentável dos recursos naturais.

A Conferência das Nações Unidas para o Meio Ambiente e o Desenvolvimento surgiu em decorrência da Assembleia Geral das Nações Unidas que ocorreu em 1984 e criou a Comissão Mundial sobre o Meio Ambiente e o desenvolvimento, conhecida como Comissão de Brundtland, que em 1987 apresentou à ONU, cristalizando o princípio do desenvolvimento sustentável, entendido como aquele que atende às necessidades das gerações atuais sem comprometer a capacidade de as futuras gerações terem suas próprias necessidades atendidas.

Para Derani (2002, p. 167), os artigos 215, $\S 1^{\circ}$., 216 e 231 da CRFB ensejam arcabouço jurídico amplo e propício à proteção do CTA. A Lei n. 11.105, de 24 de março de 2005, regulamenta os incisos II, IV e V do $\S 1^{\circ}$, do artigo 225 da CRFB.

O Acordo de Paris incorporou os conhecimentos tradicionais como elementos de adaptação e inovação. Trata-se do reconhecimento dos direitos dos povos indígenas e o acesso direto a financiamentos para projetos relacionados às mudanças climáticas, uma questão de sobrevivência debatida no Fórum Internacional de Povos Indígenas sobre $\mathrm{Mu}-$ danças Climáticas, que é instância da Convenção do Clima da ONU, onde lideranças de povos indígenas de diferentes regiões do mundo discutem, aproximam conceitos e posi- 
cionamentos em relação a essas negociações. Os povos indígenas protegem as florestas e podem contribuir enormemente para evitar mais emissões de gases de efeito estufa.

No âmbito regional da América Latina, a Decisão 391 da Comissão de Acordo de Cartagena sobre o Regime Comum sobre Acesso aos Recursos Genéticos, de 1996. A partir da CDB aprofundou o debate sobre a necessidade de promover, preservar e proteger os CTAs. Em nível infraconstitucional, destaca-se: a Lei n. 9.279, de 14 de maio de 1996 (Lei de Proteção à Propriedade Intelectual); a Lei n. 9.456, de 25 de abril de 1997 (Lei de Cultivares); a MP n. 2.186-16, de 23 de agosto de 2001 (que regula o acesso ao patrimônio genético) e o Decreto n. 4.339, de 22 de agosto de 2002.

Urge ressaltar o Decreto n. 5.459, de 7 de junho de 2005, que regulamenta o artigo 30 da MP n. 2.186-16 sobre o acesso ao patrimônio genético e ao CTA, dota os povos tradicionais de autoridade para decidir sobre seus conhecimentos, assegura o direito de conhecer o uso de tais informações e se o uso gerará benefícios econômicos. Reconheceu a natureza coletiva dos conhecimentos tradicionais. Porém, o referido decreto não criou mecanismos que assegurem os conhecimentos tradicionais, utilizaram a tutela dos direitos de propriedade intelectual, inadequada à natureza coletiva.

Também merece destaque o Decreto n. 5.813, de 2006 (que garante acesso seguro e uso racional de plantas medicinais e fitoterápicos, a promoção do uso sustentável da biodiversidade, o desenvolvimento da cadeia produtiva e da indústria nacional e instituiu a Política Nacional de Plantas Medicinais e Fitoterápicos), e o Decreto n. 6.041/2007 (institui a Política de Desenvolvimento da Biotecnologia). Destacam-se as leis estaduais do Acre (Lei n. 1.235/97) e do Amapá (Lei n. 388/97).

Bem intangível é o produto da mente e da consciência humana, capaz de manifestação exterior que possa ser difundida ou reproduzida, pode ser monopolizado e tutelado por lei. Trata-se de realidade que não possui forma, produto da criação do espírito humano, que o direito valora como objeto dotado de direitos subjetivos.

Propriedade intelectual é a proteção do produto advindo da intervenção dos seres humanos no meio em que se encontram, essas criações são oriundas do seu intelecto, sendo resultado das primeiras formas de luta pela sobrevivência num ambiente hostil, para assim poder garantir a espécie.

Massaguer (1996, p. 321) entende que a proteção do sistema de proteção intelectual "é apropriada e necessária para cumprir as exigências normativas vigentes de proteção jurídica dos conhecimentos tradicionais". O primeiro argumento é sua natureza imaterial, a mesma natureza de todas as criações humanas objeto dos direitos de propriedade intelectual. O segundo fundamento é o mecanismo de desapropriação, que controla a utilização e preserva os conhecimentos tradicionais frente a sua indevida apropriação por terceiros.

O sistema de patentes é inadequado para a proteção dos conhecimentos tradicionais, porque incompatível com as práticas e culturas dos povos tradicionais, que podem ver seu modo de viver arruinado pela lógica da economia de mercado. Os povos tradicionais tendem a não gozar dos direitos de propriedade sobre seus conhecimentos, inovações e práticas. Um curandeiro tradicional, por exemplo, dificilmente será chamado de inventor. Conhecimentos tradicionais são direitos intelectuais coletivos pelas características, natureza e fundamento das crenças intelectuais tradicionais, distintas daquelas protegidas pelo sistema de propriedade intelectual. 
Patentes possuem prazo de vigência determinado, concedem um monopólio temporal sobre a utilização de seu objeto. É impossível precisar o momento de criação dos conhecimentos tradicionais e definir marco temporal de vigência para qualquer direito intelectual coletivo. Patentes monopolizam e individualizam os conhecimentos tradicionais criados e desenvolvidos de forma coletiva, de geração a geração,

Patentes protegem criações que constituem novidade e representam atividade inventiva. Para Kishi (2004), a possibilidade de patentear o conhecimento tradicional já se encontra excluída, uma vez que um conhecimento ancestral não pode ser considerado novo. Patente sobre recursos genéticos é incompatível com a soberania, pois qualquer patente sobre formas de vida deve ser proibida.

Assim como ocorre no sistema de patentes, são diversas as razões que fazem as normas do direito de autor inadequadas para proteger as criações que são originais, estabelecidas em suportes concretos que estão incluídas no conjunto de obras denominadas de literárias, artísticas ou científicas. A proteção do direito de autor é temporal, não coaduna com a antiguidade das manifestações culturais.

O direito de autor protege a obra criada pelo indivíduo e por um coletivo de pessoas não identificadas, importante para exercer os direitos morais e patrimoniais sobre a criação. A falta de titularidade individual das expressões culturais tradicionais impossibilita a defesa. Em relação às normas do direito de autor, a maioria das expressões culturais já estaria em domínio público e os povos tradicionais já não teriam direito patrimonial sobre elas.

Deter um conhecimento sobre algo é uma forma de inovação, na medida em que esse conhecimento possa representar um possível desenvolvimento de produto ou processo inovador. $\mathrm{O}$ detentor do conhecimento é um agente inovador, merecedor de recompensa que o fará continuar sendo um inovador, representa uma justa retribuição pelos esforços empreendidos pela guarda e compartilhamento desse conhecimento, muitas vezes ancestral. A CDB, o Protocolo de Nagoia e a CRFB reconhecem esse conhecimento e preveem a necessidade de sua recompensa.

A grande indústria sempre defendeu que a recompensa pelo uso de CTA no desenvolvimento de seus produtos, em primeiro lugar, representaria um entrave ao processo inovador, pois colocaria mais um detentor da propriedade. É incapaz de deter o processo de busca de alguma forma de reconhecimento ao detentor do CTA.

A Lei n. 13.123/2015 representa o novo marco legal da biodiversidade, cujo objetivo é delinear os bens, direitos e obrigações concernentes ao acesso e proteção do patrimônio genético e à repartição dos benefícios para conservação e uso sustentável da biodiversidade. Os que tiverem acesso ao patrimônio genético da biodiversidade brasileira e/ou do CTA se submeterão à fiscalização, restrições e repartição dos benefícios, sendo indispensável o cadastro, a autorização ou a notificação da União.

A Lei n. 13.123/2015 facilita a pesquisa envolvendo elementos da biodiversidade e coloca em risco as comunidades e o patrimônio genético nacional. Foi transformada em exceção à regra da repartição dos benefícios, em vigor desde a Rio-92, passando pelo Protocolo de Nagoia.

A ausência de restrição à concessão de patentes sobre produto que possa ter sua origem derivada de CTA, com o novo sistema a autorização foi substituída pela mera declaração, 
nada impede que uma empresa desenvolva pesquisa a partir de CTA à biodiversidade amazônica e não associe a qualquer produto acabado, e use do sistema de propriedade intelectual para obter patentes, sem distribuição de nenhum benefício às comunidades e à nação.

Na concepção de Silva (2016, p. 219), a proteção ao CTA no Brasil, efetuada pela Lei n. 13.123/2015, representa uma "tragédia normativa", porque "é claramente favorável ao capital em detrimento das populações envolvidas, não há uma justa recompensa, em alguns casos pode nem haver recompensa", falta um processo de construção democrático e atenta à dignidade dos atores envolvidos.

Em 2004, foi criado um grupo de trabalho, no âmbito da CDB, para negociar um regime internacional sobre acesso e repartição de benefícios. Após seis anos de negociações, em 29 de outubro de 2010, foi adotado em Nagoia, no Japão, o Protocolo sobre acesso a recursos genéticos e repartição justa e equitativa dos benefícios derivados de sua utilização.

O Protocolo de Nagoia é um novo tratado internacional que se baseia e apoia a implementação da CDB. Ele se reporta em particular a um dos seus três objetivos: a repartição justa e equitativa dos benefícios oriundos da utilização dos recursos genéticos. Trata-se de um acordo histórico para a governança internacional da biodiversidade e é relevante para vários setores comerciais e não comerciais envolvidos no uso e no intercâmbio de recursos genéticos.

O Protocolo de Nagoia se baseia nos princípios fundamentais de acesso e repartição de benefícios consagrados pela CDB. Esses princípios sustentam a necessidade de obtenção, pelos usuários potenciais de recursos genéticos, do consentimento prévio fundamentado do país em que o recurso genético está localizado. Assim como da negociação entre as partes e do estabelecimento de condições de acesso e uso desse recurso por meio da assinatura de termos mutuamente acordados.

Ao garantir a segurança jurídica e a promoção da repartição de benefícios, o referido Protocolo incentiva o desenvolvimento de pesquisas sobre recursos genéticos que podem levar a novas descobertas em benefício de todos. Também cria incentivos para a conservação e o uso sustentável dos recursos genéticos, aumentando a contribuição da biodiversidade para o desenvolvimento e bem-estar humano.

O referido Protocolo propõe a criação de um mecanismo multilateral mundial de repartição de benefícios para tratar dos casos resultantes da utilização dos recursos genéticos que ocorrem em áreas transfronteiriças ou em situações onde não é possível obter o consentimento prévio fundamentado. Falta definir a natureza desse mecanismo multilateral. Os benefícios repartidos por meio desse mecanismo serão utilizados para apoiar a conservação e o uso sustentável da biodiversidade em escala global.

O Protocolo de Nagoia aborda os CTAs aos recursos genéticos por meio de disposições sobre acesso, repartição de benefícios e o cumprimento das regras estabelecidas. Também contempla recursos genéticos presentes nos territórios das comunidades indígenas e locais que possuem direitos bem estabelecidos para permitir o acesso a eles.

É fundamental que o Congresso Nacional ratifique o Protocolo de Nagoia para que o Brasil possa opinar. A não ratificação pelo Brasil prejudica comunidades indígenas e quilombolas e só não foi alcançada em função das resistências da bancada ruralista no Congresso e conflitos de interesses dos setores do agronegócio. O sucesso do Protocolo depende da efetiva implementação do mesmo a nível nacional. 
Mecanismos de apoio previstos auxiliarão as suas partes signatárias com a implementação e estes incluem a designação de pontos focais nacionais e de autoridades nacionais competentes para servir como pontos de contato para obtenção de informações sobre concessão de autorização de acesso e sobre cooperação entre as partes.

As empresas transnacionais utilizam recursos naturais para buscar novos produtos e medicamentos para ampliar seu mercado. A atual lógica da transferência de tecnologias e recursos é criticada pelos povos tradicionais, pois antes detinham todos os recursos originariamente, sem necessitar de transferência.

A CDB compreende a biodiversidade como patrimônio comum da humanidade e consagra que se deve compartilhar equitativamente os recursos naturais, criando um sujeito social universal. A CDB é um documento internacional de 1992, em que participam 168 países, destinada à conservação da diversidade biológica do planeta.

Para Derani (2006, p. 73), além da preocupação com a manutenção da variedade dos ecossistemas terrestre, a Convenção busca a valorização das culturas locais, como meio para a conservação da diversidade biológica selvagem e cultivada. No que tange à biodiversidade cultivada, as decisões sobre biodiversidade agrícola na CDB com frequência fazem referência à $\mathrm{FAO}$, buscando uma sinergia para a valorização e proteção das culturas locais.

Tanto os recursos genéticos como os conhecimentos dos povos de cada país estarão amparados e protegidos por esse instrumento. O Protocolo de Nagoia é um importante instrumento internacional que complementa e garante a CDB. Em vigor desde 2014, muitos países já desfrutam de sua proteção e transparência nas relações, porém o Brasil ainda está aquém desse documento por conflitos de interesses dos setores do agronegócio e certa oposição da bancada ruralista.

\section{O TRATAMENTO SUSTENTÁVEL DOS CONHECIMENTOS TRADICIONAIS ASSO- CIADOS À BIODIVERSIDADE AMAZÔNICA}

Adota-se a classificação dimensional da sustentabilidade categorizada por Freitas (2012, p. 58-70) cujas dimensões incidem, de forma lógica e imbricada, no tratamento sustentável dos CTAs à biodiversidade amazônica.

El paradigma actual de la Humanidad es la sostenibilidad. La voluntad de articular una nueva sociedad capaz de perpetuarse en el tiempo en unas condiciones dignas. El deterioro material del planeta es insostenible, pero también es insostenible la miseria y la exclusión social, la injusticia y la opresión, la esclavitud y la dominación cultural y económica (FERRER, 2012, p. 319).

Conforme o entendimento de Boff (2012, p. 107):

Sustentabilidade é toda ação destinada a manter as condições energéticas, informacionais, físico-químicas que sustentam todos os seres, especialmente a Terra viva, a comunidade de vida e a vida humana, visando sua continuidade e ainda atender as necessidades da geração presente e das futuras, de tal forma que o capital natural seja mantido e enriquecido em sua capacidade de regeneração, reprodução e coevolução. 
A sustentabilidade é concebida em suas múltiplas ou plurais dimensões, ainda que não exista uniformização conceitual do seu termo parece evidente, pela vasta literatura que envolve a matéria, que ela é um "valor" (FREITAS, 2014, p. 32), um "princípio" (BOSSELMANN, 2015; CRUZ e GLASENAPP, 2014; FREITAS, 2014; SILVA, 2010) e um "direito fundamental" (COIMBRA, 2017).

Historicamente, a sustentabilidade foi edificada a partir do tripé dimensional ambiental, econômico e social, ou, como denominado por Canotilho (2010), "dimensão tridimensional", com grande influência da Declaração do Milênio, realizada em 2000, que proclamou a Declaração e Objetivos do Milênio para o Desenvolvimento.

A dimensão ambiental para Silva (2010, p. 18) "é a interação do conjunto de elementos naturais, artificiais e culturais que propiciem o desenvolvimento equilibrado da vida em todas as suas formas". Para Lima e Pozzobon (2005, p. 45), é a "capacidade de uma dada população de ocupar uma determinada área e explorar seus recursos naturais sem ameaçar, ao longo do tempo, a integridade ecológica do meio ambiente".

A dimensão ambiental ou ecológica da sustentabilidade é substrato da própria história e da relação do homem com a natureza ao longo dos séculos. O uso predatório dos recursos ambientais por parte dos homens, associado às tragédias ambientais, obrigou o debate sob o novo enfoque, repensando as bases capitalistas de exploração do meio ambiente. Portanto, os problemas relacionados à dimensão ambiental da sustentabilidade são os riscos à biodiversidade.

Garcia (2011, p. 164) adverte que é impossível discutir a sustentabilidade econômica de forma dissociada da ambiental. Para Freitas (2012), a pobreza, a miséria, a ausência de saneamento básico e tudo mais que comprometa a dignidade humana por ausência de recursos materiais mínimos à saudável qualidade de vida não é sustentável.

A dimensão econômica da sustentabilidade visa ao desenvolvimento da economia com a finalidade de gerar melhor qualidade de vida às pessoas. Passou a ser considerada no contexto da sustentabilidade porque não haveria possibilidade de retroceder nas conquistas econômicas de desenvolvimento alcançadas pela sociedade mundial; e o desenvolvimento econômico estaria interligado com a dimensão social do princípio da sustentabilidade, pois é necessário para a diminuição da pobreza. Dessa forma, os problemas associados à dimensão econômica da sustentabilidade são a biopirataria e a apropriação indevida dos conhecimentos tradicionais.

Para Garcia (2011, p. 210-215), a dimensão social implica melhoria na qualidade de vida da coletividade, na redução da discrepância oriunda da injusta distribuição de renda, ligada à garantia dos direitos sociais e da dignidade da pessoa humana. Com lastro teórico nas grandes conferências globais sobre o meio ambiente, a referida autora sustenta que a pobreza é um dos grandes desastres da humanidade. Os privados do mínimo existencial à sua sobrevivência não têm garantido direitos sociais básicos do artigo $6^{\circ}$. da CRFB. Negar a dignidade humana aos que vivem em extrema pobreza contribui para que depredem o meio ambiente.

Para Neves (2011, p. 17), "o conceito de sustentabilidade social caracteriza-se pela melhoria da qualidade de vida da população, equidade na distribuição de renda e de diminuição das diferenças sociais, com participação e organização popular”. 
Para Sachs (2002, p. 85-89), a dimensão social se refere ao "alcance de um patamar razoável de homogeneidade social, com distribuição de renda justa, emprego pleno e/ou autônomo com qualidade de vida decente e igualdade no acesso aos recursos e serviços sociais". Mencionado autor se refere à concretude dos direitos sociais. Os problemas relacionados à dimensão social da sustentabilidade são a saúde e a qualidade de vida dos povos tradicionais da Amazônia.

Para o alcance da sustentabilidade dos conhecimentos tradicionais associados à biodiversidade amazônica sugere-se: a cooperação, a solidariedade, o equilíbrio e a educação ambiental. Cooperação é instrumento para proteger direitos humanos e integra países. Possibilita a conservação e utilização sustentável dos conhecimentos tradicionais associados. No cenário internacional de interdependência, Kinoshita (1999, p. 57) explica que há “dever de cooperação para atingir o desenvolvimento mundial".

Ferrer (2013, p. 77) compreende que a sociedade global impõe a "preminencia de la solidaridad planetaria en nuestras relaciones, (...) el Derecho público (...) que impone la solidaridad colectiva por encima de los intereses parciales o individuales. Ese es el fundamento del derecho de la sostenibilidad".

O equilíbrio é a base da educação, é a busca de outro mundo possível para a vida com qualidade. O desrespeito ao equilíbrio da natureza cobra altíssimo preço. Para Gadotti (2000, p. 78), o "equilíbrio dinâmico com o outro e com o meio (...) é harmonia entre os diferentes" e sugestão de alcance da sustentabilidade.

A educação ambiental é uma forma de intervenção no mundo, "prática de liberdade", ato político e principal instrumento de mudança na "busca de outro mundo possível" (FREIRE, 2004, p. 19). Trata-se de um instrumento para alcançar a sustentabilidade dos conhecimentos tradicionais associados à biodiversidade amazônica.

\section{CONSIDERAÇões FINAIS}

O trabalho em testilha constatou a imprescindível inter-relação dos conhecimentos tradicionais dos povos da Amazônia com a conservação ambiental, sob o viés do tratamento sustentável dos conhecimentos tradicionais à biodiversidade amazônica, e possibilitou o estudo da proteção jurídica dos conhecimentos tradicionais associados à biodiversidade amazônica.

O trabalho requereu um esquema conceitual que lhe conferiu um instrumental teórico suficientemente articulado para a sua problemática. Foi utilizado o método indutivo na fase de investigação e na fase de tratamento dos dados. Nas diversas fases da pesquisa, foram acionadas as técnicas do referente, da categoria, do conceito operacional, da pesquisa bibliográfica e do fichamento.

O trabalho evidenciou a sustentabilidade dos conhecimentos tradicionais associados à biodiversidade amazônica e a necessidade de melhorar a proteção jurídica desses importantes conhecimentos geracionais. $\mathrm{O}$ aludido problema concentrou seus esforços na busca de substituir o sistema de patentes, bem como, o sistema de garantia dos direitos de autor, inadequados para proteger as comunidades tradicionais. Com vistas a esse fim, percorreu- 
-se, do ponto de vista do marco de referência, a bibliografia de relevância já tornada pública em relação ao tema de estudo.

O equacionamento do problema suscitou na hipótese de que a floresta amazônica está inserida além do Brasil, em territórios de outros países sul-americanos como Suriname, Venezuela, Guiana, Colômbia, Equador, Peru e Bolívia, além da Guiana Francesa, portanto, sua conservação exige, necessariamente, o compromisso e a organização de todos esses países.

O presente trabalho atingiu o objetivo geral que foi analisar a proteção jurídica dos conhecimentos tradicionais associados à biodiversidade amazônica, considerando a imprescindível inter-relação dos conhecimentos tradicionais dos povos da Amazônia com a conservação ambiental.

O trabalho situou a região amazônica, elucidou o conceito de conhecimentos tradicionais associados à biodiversidade amazônica e os povos tradicionais. Analisou a legislação aplicada aos conhecimentos tradicionais. Estudou a proteção jurídica dos conhecimentos tradicionais associados à biodiversidade amazônica, bem como, analisou a limitada proteção que oferecem os direitos nacionais e a tutela internacional.

O trabalho ressaltou que o sistema de patentes e o sistema de garantia dos direitos de autor são inadequados para proteger as comunidades tradicionais. Analisou o tripé dimensional (ambiental, econômico e social), imbricando-o metodologicamente por estreita pertinência temática e lógica ao objeto do trabalho.

Dessa forma, o trabalho cumpriu os objetivos específicos propostos, a saber: verificou no ordenamento vigente o arcabouço jurídico aplicado aos conhecimentos tradicionais dos povos da Amazônia; enfatizou a limitada proteção que oferecem os direitos nacionais e a tutela internacional em vigor relacionada aos conhecimentos tradicionais associados à biodiversidade amazônica, considerando sua imprescindível inter-relação com a sustentabilidade; sugeriu o alcance da sustentabilidade no tratamento dos conhecimentos tradicionais associados à biodiversidade amazônica.

\section{REFERÊNCIAS}

BERKES, Fikret. Context of traditional ecological knowledge. In: Sacred Ecology: traditional ecological knowledge and resource management. Philadelphia, 1999.

BOFF, Leonardo. Sustentabilidade: o que é - o que não é. Petrópolis-RJ: Vozes, 2012.

BOSSELMANN, Klaus. O princípio da sustentabilidade: transformando direito e governança. Tradução de Phillip Gil França. São Paulo: RT, 2015.

BRASIL. Decreto Legislativo n. 2, de 1994. Aprova o texto da Convenção sobre Diversidade Biológica. Disponível em: http://www2.camara.leg.br/legin/fed/decleg/19 94/decretolegislativo-2-3-fevereiro-1994-358280-publicacaooriginal-1-pl.html. Acesso em: 20 dez. 2018. 
BRASIL. Lei n. 13.123, de 20 de maio de 2015. Disponível em: http://www.planalto. gov. br/ccivil_03/_Ato 2015-2018/2015/Lei/L13123.htm. Acesso em: 15 jul. 2019.

BROWN JÚNIOR, Keith; FREITAS, André Vitor Lucci. Diversidade biológica no Alto Juruá: avaliação, causas e manutenção. In: CUNHA, Manuela Carneiro da; ALMEIDA, Mauro Barbosa de. (Org.). Enciclopédia da Floresta. O Alto Juruá: práticas e conhecimentos das populações. São Paulo: Companhia das Letras, 2002.

CANOTILHO, Joaquim José Gomes. O princípio da sustentabilidade como princípio estruturante do Direito Constitucional. Revista de Estudos Politécnicos Polytechinical Studies Review, v. 8, n. 13, 2010. Disponível em: <http://www.scielo.oces.mctes.pt/ pdf/tek/ n13/n13a02>. Acesso em: 16 jul. 2019.

COIMBRA, Wilber Carlos dos Santos. A tutela da sustentabilidade exercida pelos Tribunais de Contas como garantia de efetividade dos atos da Administração Pública. Tese (Doutorado em Ciência Jurídica). Curso de Doutorado em Ciência Jurídica, Universidade do Vale do Itajaí, Santa Catarina, 2017.

CRUZ, Paulo Márcio; GLASENAPP, Maikon Cristiano. Governança e sustentabilidade: constituindo novos paradigmas na pós-modernidade. Revista Direito e Liberdade, Natal-RN, v. 16, n. 2, p. 163-186, mai./ago., 2014.

DERANI, Cristiane. Alimento e biodiversidade: fundamentos de uma normatização. Hiléia. Revista de Direito Ambiental da Amazônia, ano 3, n. 4, Manaus, 2006.

. Patrimônio genético e conhecimento tradicional associado: considerações jurídicas sobre seu acesso. In: LIMA, André (Org.). O Direito para o Brasil Socioambiental. Porto Alegre: Sergio Fabris, 2002.

FERRER, Gabriel Real. Calidad de vida, medio ambiente, sostentabilidad y cidadanía. Construímos juntos el futuro? Revista Novos Estudos Jurídicos - NEJ, Itajaí-SC, v. 17, n. 3, p. 310-326, set./dez., 2012. Disponível em: http://siaiweb06.univali.br/seer/ index.php/ nej/article/view/4202. Acesso em: 15 jul. 2019.

. Sostenibilidad, Transnacionalidad y Trasformaciones del Derecho. In: SOUZA, Maria Cláudia da Silva Antunes de; GARCIA, Denise Schmitt Siqueira (Orgs.); FERRER, Gabriel Real et al. Direito ambiental, transnacionalidade e sustentabilidade. Livro eletrônico. Itajaí-SC: UNIVALI, 2013.

FREIRE, Paulo. Pedagogia da autonomia. Rio de Janeiro: Paz e Terra; Anca/MST, 2004.

FREITAS, Juarez. Sustentabilidade: direito ao futuro, 2. ed. Belo Horizonte: Fórum, 2012. 
FREITAS, Thiago Pereira de. Sustentabilidade e as contratações públicas. Rio de Janeiro: Lumen Juris, 2014.

GADOTTI, Moacir. Pedagogia da terra, 2. ed. São Paulo: Cortez, 2000.

GARCIA, Denise Schmitt Siqueira. GARCIA, Denise Schmitt Siqueira. El principio de sostenibilidad y los puertos: a atividade portuária como garantidora da dimensão econômica e social do princípio da sustentabilidade, 2011, 451s. Tese. (Doctorado em Derecho Ambiental y Sostenibilidad de la Universidad de Alicante - UA). Espanha, Universidade de Alicante, 2011.

GREGORI, Isabel Cristine da. Os conhecimentos tradicionais e a biodiversidade. In: TYBUSCH, Jerônimo Siqueira; ARAÚJO, Luiz Ernani Bonesso; SILVA, Rosane Leal da (Orgs.). Revista Direitos Emergentes na Sociedade Global - REDESG. Anuário do Programa de Pós-Graduação Stricto-Sensu, Mestrado em Direito da Universidade Federal de Santa Maria-RS. Ijuí-RS: Unijui, 2013.

KINOSHITA, Fernando. El tratado de libre comercio entre la Unión Europea y el Mercosur: consolidación de un marco jurídico-económico internacional. Tesis Doctoral. Madrid: Universidad Pontificia Comillas/ICADE, 1999.

KISHI, Sandra Akemi Shimada. Tutela jurídica do acesso à biodiversidade no Brasil (2004). Disponível em: http://www.museu-goeldi.br/institucional/Sandra_A_S.pdf. Acesso em: 10 jul. 2019.

LIMA, Deborah; POZZOBON, Jorge. Amazônia socioambiental. Sustentabilidade ecológica e diversidade social, v. 19, n. 54, São Paulo, mai./ago., 2005. Disponível em:<http:// www.scielo.br/scielo.php?pid $=\mathrm{S} 0103-142005000200004 \&$ script $=$ sci_arttext $>$. Acesso em: 10 jul. 2019.

MASSAGUER, José. De nuevo sobre el agotamiento comunitário del Derecho de Patente nacional. Comentario a la Sentencia del Tribunal de Justicia de las Comunidades Europeas de 5 de diciembre de 1996, assuntos acumulados C-267/95 y C-268/95, Merck \& Co. Inc. et al y Beecham Group plc c. Europharm of Worthing Ltda. Actas del Derecho Industrial y Derecho de Autor, Tomo XVII, 1996.

MATHEUS, Ana Carolina Couto. A regulação transnacional sustentável dos conhecimentos tradicionais dos povos amazônicos. In: PIFFER, Carla; BALDAN, Guilherme Ribeiro; CRUZ, Paulo Márcio (Orgs.). Transnacionalidade e sustentabilidade: dificuldades e possibilidades em um mundo em transformação, v. 1, p. 93-113, Porto Velho-RO: Emeron, 2018.

NEVES, Lafaite Santos. Sustentabilidade: anais de textos selecionados do $5^{\circ}$. seminário sobre sustentabilidade. Curitiba-PR: Juruá, 2011. 
SACHS, Ignacy. Caminhos para o Desenvolvimento Sustentável. Rio de Janeiro: Garamond, 2002.

SANTILLI, Juliana. Socioambientalismo e novos direitos. São Paulo: Petrópolis, 2005.

SILVA, José Afonso da. Direito Ambiental Constitucional, 8. ed. São Paulo: Malheiros, 2010 .

SILVA, José Everton da. A proteção do conhecimento tradicional associado sob a lógica da análise econômica do Direito: uma questão constitucional baseada na dignidade da pessoa humana, 376s. Tese (Doutorado). Curso de Doutorado em Ciência Jurídica, Universidade do Vale do Itajaí, Santa Catarina, 2016.

\section{ana Carolina Couto Matheus}

Doutora em Ciência Jurídica pela UNIVALI-SC. Mestre em Direito pela UNIPAR-PR. Especialista em Direito Tributário pela UnP-RN. Professora Adjunta III do CCJSA da UFAC-AC. Coordenadora do Núcleo de Prática Jurídica e Estágios. Professora da Pós-Graduação. Advogada. carolcoutomatheus@hotmail.com.

Submetido em: 25-7-2019

Aceito em: 31-8-2020 